\title{
ASSESSMENT OF SOURCE CONTRIBUTIONS TO THE URBAN AIR QUALITY FOR THE BRISTOL CLAIRCITY PILOT CASE
}

\author{
KEVIN OLIVEIRA ${ }^{1}$, VERA RODRIGUES ${ }^{1}$, SILVIA COELHO ${ }^{1}$, ANA PATRÍCIA FERNANDES ${ }^{1}$, \\ SANDRA RAFAEL ${ }^{1}$, CARLOS FARIA ${ }^{1}$, JOANA FERREIRA ${ }^{1}$, CARLOS BORREGO $^{1}$, TROND HUSBY ${ }^{2}$, \\ IASON DIAFAS ${ }^{2}$, PER SIEVERTS NIELSEN ${ }^{3}$, XIUFENG LIU $^{3}$, ANGREINE KEWO $^{3}$, CARLO TROZZI $^{4}$, \\ ENZO PISCITELLO ${ }^{4}$, KRIS VANHERLE $^{5}$, SVEIN KNUDSEN ${ }^{6}$, EVERT BOUMAN $^{6}$, JO BARNES $^{7}$, \\ STEPHAN SLINGERLAND ${ }^{8}$, ENDA HAYES 7 , HANS BOLSCHER ${ }^{8} \&$ MYRIAM LOPES $^{1}$ \\ ${ }^{1}$ CESAM and Department of Environment and Planning, University of Aveiro, Portugal \\ ${ }^{2}$ Planbureau voor de Leefomgeving, The Netherlands \\ ${ }^{3}$ Danmarks Tekniske Universitet, Denmark \\ ${ }^{4}$ TECHNE Consulting SRL, Italy \\ ${ }^{5}$ Transport and Mobility Leuven, Belgium \\ ${ }^{6}$ Norsk Institutt for Luftforskning, Norway \\ ${ }^{7}$ University of the West of England, UK \\ ${ }^{8}$ Trinomics Bv, The Netherlands
}

\begin{abstract}
The world's population has been growing continuously, with most people inhabiting urban settlements. Furthermore, air pollution has become a growing concern, mainly in densely populated cities, where human health is threatened by acute air pollution episodes. The H2020 ClairCity project aims to substantially improve future air quality and carbon policies in European cities by initiating new modes of engaging citizens, stakeholders and policy makers. ClairCity applies an innovative quantification framework developed to assess environmental, health and economic impacts. In this work, the quantification framework was applied and calibrated for the baseline situation in Bristol, the ClairCity pilot city. The second-generation Gaussian model URBAIR was set up to simulate $\mathrm{NO}_{2}$ and particulate matter (PM) concentrations for the entire year of 2015. An analysis of source contribution was performed providing information on the contributions of different source sectors (e.g. road transport, industrial, residential and commercial) to $\mathrm{NO}_{2}$ and $\mathrm{PM}$ concentrations. The results point to a predominant contribution of road transport sector of $53 \%$ to $\mathrm{NO}_{2}$ concentrations in Bristol, while the residential sector is the main contributor (with a contribution of $82 \%$ ) to particulate matter concentrations, mainly linked with a high use of solid biomass combustion in this sector. These results can be powerful to support the design of air quality management plans and strategies and to forecast potential benefits of reducing emissions from a particular source category.
\end{abstract}

Keywords: H2020 programme, ClairCity, air pollution reduction, citizens engagement, European cities, urban areas.

\section{INTRODUCTION}

As the population continues to grow exponentially and moving from rural to urban areas this results in a large population density in urban settlements, which contributes to a high pressure over the environment. Furthermore, air pollution represents a global threat that leads to major impacts on human health and ecosystems. It represents a public health concern mainly due to population's long-term exposure to high levels and acute air pollution episodes. According to the World Health Organization (WHO), in 2015, in the European region exposure to air pollution contributed in 391000 premature deaths attributed to $\mathrm{PM}_{2.5}$ and to 76,000 premature deaths linked to $\mathrm{NO}_{2}$ [1]. The most common reasons for premature death attributable to air pollution are due to noncommunicable diseases - notably cardiovascular diseases, stroke, chronic obstructive pulmonary disease and lung cancer. Air pollution also increases the risks for acute respiratory infections. In terms of exposure, both short and long- 
term exposure to air pollution can lead to reduced lung function, respiratory infections and aggravated asthma, where children and older people, as well as, people with previous health conditions, are more vulnerable and therefore more likely to be affected by air pollution. In Europe, currently the average loss in life expectancy due to fine particles is about 5 months but can be more than 12 months in some urban areas [1]-[4].

According to the European Environment Agency's estimates of the urban population exposure to air pollution between 2014 and 2016, a substantial percentage of the urban population in the EU-28 was exposed to concentrations of certain air pollutants above EU limit and this number is even higher when the WHO air quality guideline values were applied. In terms of fine particulate matter $\left(\mathrm{PM}_{2.5}\right), 6-8 \%$ of the EU-28 urban population was exposed to concentrations above the EU limit value, while $74-85 \%$ was exposed to concentrations above the WHO guideline value. For $\mathrm{PM}_{10}$ the exposure estimates were $13-19 \%$ above the EU limit value and $42-52 \%$ above the WHO guideline value and for Nitrogen dioxide $\left(\mathrm{NO}_{2}\right)$ the estimates were around $7-8 \%$ of the EU-28 urban population were exposed to levels above the limit value, both from the EU and the WHO guidelines values [1], [5].

ClairCity project aims to improve future air quality and carbon policies in six pilot European cities (Amsterdam, Bristol, Sosnowiec, Genoa, Ljubljana and the Aveiro Region) by introducing new approaches to engage citizens, stakeholders and policymakers. Placing the citizen and their behaviours at the centre of both the problems and the solutions of the decision-making will allow citizens and other stakeholders to discuss the role of air quality and carbon policies for citizens' health, general well-being and future quality of life.

This work applies and calibrates for the baseline situation of Bristol city a quantification framework to assess the impacts on air quality and population exposure focus on $\mathrm{NO}_{2}, \mathrm{PM}_{10}$ and $\mathrm{PM}_{2.5}$ concentrations. The second-generation Gaussian model URBAIR was set-up to simulate $\mathrm{NO}_{2}$ and particulate matter concentrations for the entire year of 2015. For these pollutants, an analysis of source contribution was performed providing information on the concentration contributions of different source sectors (e.g. road transport, industrial, residential and commercial sectors).

\section{METHODOLOGY}

Bristol, the pilot case study of ClairCity project, is a city located in South West England with an estimated population of roughly 454,000 inhabitants.

The assessment of source contributions from distinct emission sectors to the simulated air quality is performed for the pilot case study of the ClairCity project, based on the quantification framework established under the project. This framework consists of an assessment of the impact of a set of policies on emissions, air quality, human health and related costs. The air quality assessment is performed covering distinct spatial scales: the WRF modelling system is applied to an European domain using a horizontal grid resolution of 0.25 degrees, and then to a regional domain covering the urban area of Bristol using as horizontal resolution 0.05 degrees, both in an hourly basis. The air quality at urban scale is simulated using the second-generation Gaussian model URBAIR for the computational domain over the urban area of Bristol of $20 \mathrm{~km}$ x $20 \mathrm{~km}$ with a horizontal grid resolution of $200 \mathrm{~m}$ x $200 \mathrm{~m}$. The URBAIR model has been implemented in previous works for a set of urban applications [6], [7] and tested against measured data.

The baseline simulations were performed using as input data the meteorological vertical profiles provided by the WRF model. The air quality simulations were performed for the fullyear in an hourly basis. The concentrations of $\mathrm{NO}_{2}, \mathrm{PM}_{10}$ and $\mathrm{PM}_{2.5}$ were simulated using the emission rates available on the ClairCity emission database. The ClairCity emission database includes point sources with the emission rates of the large industry sources, the line sources 
with the road traffic emissions and the area sources covering the residential, commercial and industrial emissions. The database is built from distinct emission sectors, in line with statistics by sector, by time of day, establishing the link with citizen's behaviour. The air quality is assessed for the current situation through modelling tools, evolving towards the comparison of the simulation outputs with observations.

\subsection{Background concentrations}

The quantification framework covered the simulation of the transport, commercial and residential, and the industrial emission sectors. As a result of the absence of other relevant emission sectors within the domain and also due to important transboundary pollution, it lead to a clear underestimation of the simulated concentrations. Therefore, to overcome this issue, other remaining sectors were accounted as background. For the background quantification, a methodology was applied based on the background concentration maps published by the UK's Department for Environment Food and Rural Affairs (Defra). The air quality maps produced by Defra present concentration values by different sectors and corresponded to an annual mean in a spatial resolution of $1 \mathrm{~km} \times 1 \mathrm{~km}$. For this case study, to the simulated $\mathrm{NO}_{2}$ concentrations were added the concentrations available on the Defra database linked with the contributions from the categories of aircraft, rail, other and rural, whereas for $\mathrm{PM}_{10}$ and $\mathrm{PM}_{2.5}$ the added categories where: rail, other, secondary PM, residual and salt.

\subsection{Model adjustment procedure}

The calibration of the simulations results along with the added background concentrations were made through an adjustment method by comparing the obtained values with measured data from 2015. For $\mathrm{NO}_{2}$ concentrations the measured data available include 107 diffuse tubes distributed mainly over Bristol's urban area of which 96 classify as roadside, four as kerbside and seven as urban background tubes. In addition, four continuous measurement points (two roadside, one kerbside, and one urban background sites) together with St Paul's urban background station. The values from the diffusion tubes indicate an average concentration of $42.1 \mu \mathrm{g} . \mathrm{m}^{-3}$, while the maximum concentration stands around $91.2 \mu \mathrm{g} . \mathrm{m}^{-3}$. At St Paul's station, the $\mathrm{NO}_{2}$ annual average concentration was equal to $22.5 \mu \mathrm{g} \cdot \mathrm{m}^{-3}$. The continuous measuring devices measured an average value of $36.0 \mu \mathrm{g} . \mathrm{m}^{-3}$ with a maximum concentration of $44.2 \mu \mathrm{g} . \mathrm{m}^{-3}$.

The adjustment corresponds to a linear regression between the simulated values and the corresponding matching points for all the measured data. The result of the linear regression was a slope of 1.615, which was used as a correction factor to be applied over the whole domain.

In case of particulate matter, there is limited measured data, and consequently the adjustment performed only takes into account measurements from St Paul's station. In 2015, the annual average concentration for $\mathrm{PM}_{10}$ was $14.9 \mu \mathrm{g} . \mathrm{m}^{-3}$ and for $\mathrm{PM}_{2.5}$ was $10.6 \mu \mathrm{g} . \mathrm{m}^{-3}$.

\section{RESULTS}

ClairCity focuses particularly on the transport and energy related behaviour of Bristol citizens and its contribution to air pollution and carbon emissions. The application of the quantification framework comprises the simulation of the transport, industrial, residential and commercial emission sectors. The assessment of impacts was performed in terms of air quality and population exposure focus on $\mathrm{NO}_{2}, \mathrm{PM}_{10}$ and $\mathrm{PM}_{2.5}$ concentrations. 


\subsection{Air quality maps and exposure}

Fig. 1 shows the annual average concentration fields for $\mathrm{NO}_{2}, \mathrm{PM}_{10}$ and $\mathrm{PM}_{2.5}$ for Bristol with the adjustment factor applied and the background added over the domain. For each contour map, the scale limits are set by the EU limit for each pollutant.

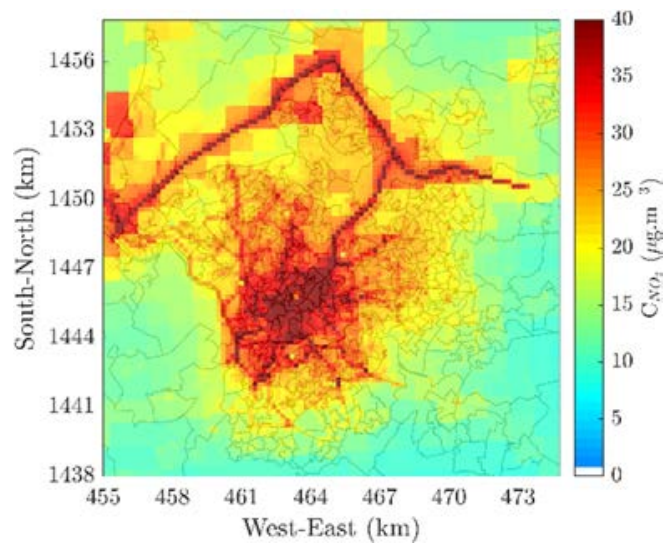

(a)

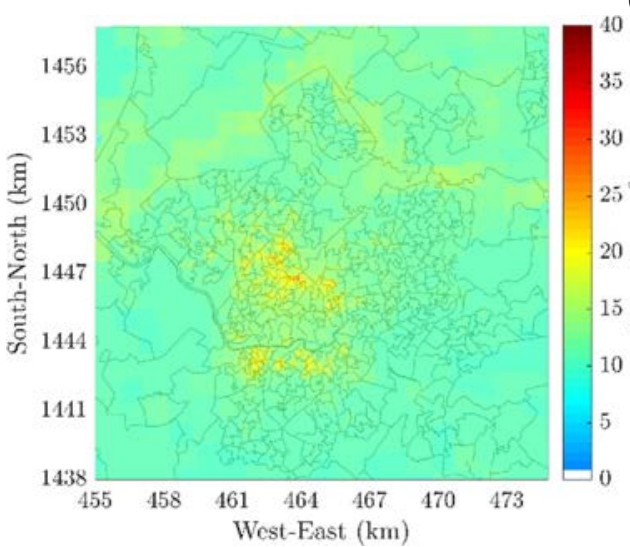

(b)

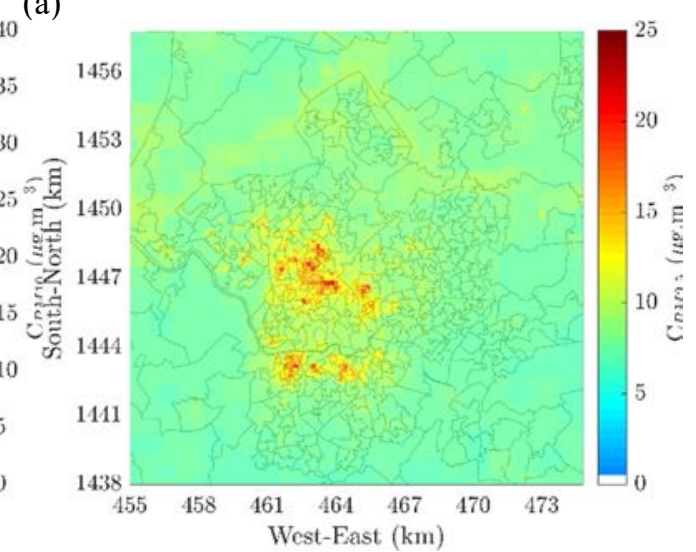

(c)

Figure 1: Contour maps of the annual average concentrations of (a) $\mathrm{NO}_{2}$; (b) $\mathrm{PM}_{10}$; and (c) $\mathrm{PM}_{2.5}$, over the urban area of Bristol.

Fig. 1(a) shows $\mathrm{NO}_{2}$ contour maps where it is easily identifiable the major highways, such as M4 and M5 on the north of the domain, and the M32 that connects the M4 to the urban centre. These major roads and including the city centre prove to be the main locations where higher concentration values are attained. Fig. 1(b) and (c) shows contour maps for $\mathrm{PM}_{10}$ and $\mathrm{PM}_{2.5}$, respectively. For both maps, the higher values are achieved in the centre of the urban area, mainly caused by residential and commercial combustion but also increased by the existing heavy traffic. However, for particulate matter no exceedances of the EU legal limits are registered. Air quality results indicate a maximum value of $91.2 \mu \mathrm{g} \cdot \mathrm{m}^{-3}$ for $\mathrm{NO}_{2}$, of $25.1 \mu \mathrm{g} . \mathrm{m}^{-3}$ for $\mathrm{PM}_{10}$ and for $\mathrm{PM}_{2.5}$ of $22.3 \mu \mathrm{g} . \mathrm{m}^{-3}$. 
As previously mentioned there was a total of 111 measurement points with available data for $\mathrm{NO}_{2}$. The applied methodology is the same for all the selected pollutants, therefore only $\mathrm{NO}_{2}$ is presented. Fig. 2 shows the simulated values of $\mathrm{NO}_{2}$ for each computational cell corresponding to the location of the measurement point, the simulation results with the added background concentrations and the final concentrations, with the background value added to the simulated concentrations as well as the adjustment factor. For the computational cells corresponding to the location of a measurement equipment the final concentration (simulation + background + adjustment) is equal to the real measured concentration at the same location.

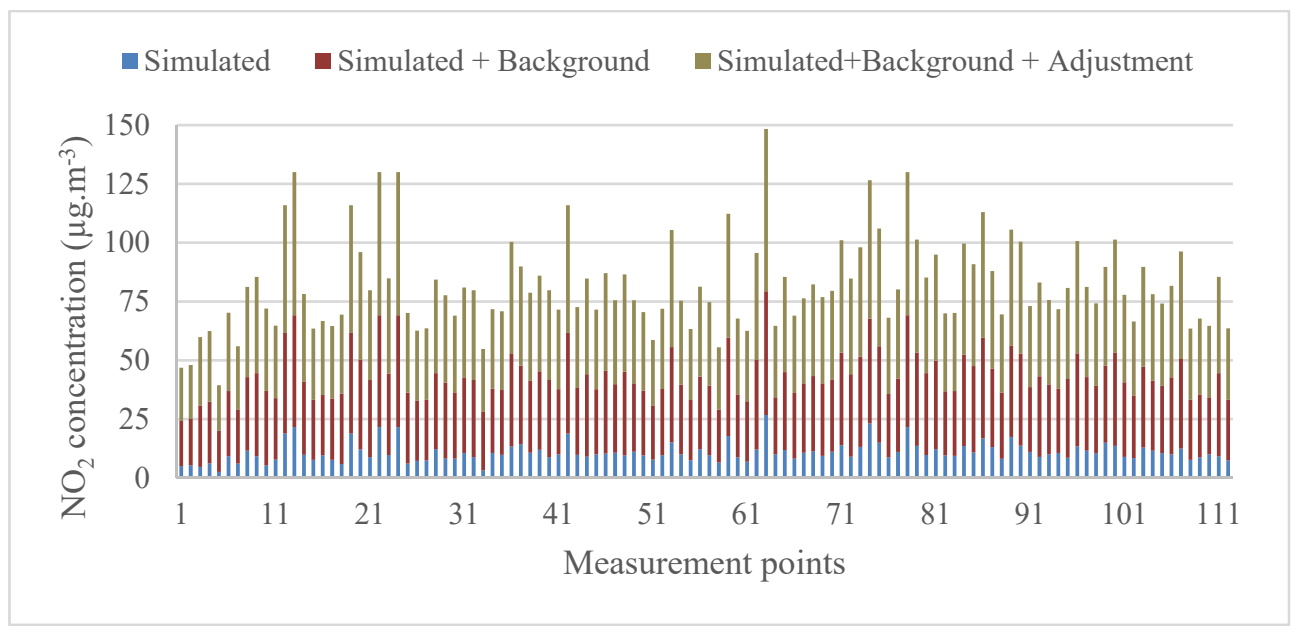

Figure 2: Comparison of $\mathrm{NO}_{2}$ concentrations for each computational cell corresponding to the location of a measurement point, including the simulated values, the simulation values with added background and the simulation values with the background concentrations together with the adjusted values.

Fig. 2 denotes the underestimation between the simulation results and the measurements, already identified before. Although the simulated maximum values are achieved in the same points as the maximum measured concentrations. The underestimation reduces significantly when the background concentrations are added.

Table 1 presents the population of Bristol that is potentially exposed to concentrations above the EU and WHO Guidelines limits. For $\mathrm{NO}_{2}$ the limits established by the EU and the WHO are equivalent, being $40 \mu \mathrm{g} . \mathrm{m}^{-3}$ for the annual mean. As for particulate matter, the limits diverge between both standards, with WHO showing much firmer limits. $\mathrm{PM}_{10}$ values under the EU annual mean limits are $40 \mu \mathrm{g} \cdot \mathrm{m}^{-3}$ and under WHO guidelines are $20 \mu \mathrm{g} \cdot \mathrm{m}^{-3}$, for $\mathrm{PM}_{2.5}$, the EU established for the annual mean limit value of $25 \mu \mathrm{g} \cdot \mathrm{m}^{-3}$ and for the WHO limits it's established at $10 \mu \mathrm{g} \cdot \mathrm{m}^{-3}$.

As presented in Table 1, 5\% of Bristol population are exposed to concentration values of $\mathrm{NO}_{2}$ above the EU limits and, although the particulate matter are below the EU limits, when stricter limits (WHO guidelines) are applied the number of inhabitants exposed becomes significant. When looking at the domain grid cells with values over the WHO limits, for $\mathrm{PM}_{2.5}$ the area covered is $7 \%$ and for $\mathrm{PM}_{10}$ the area covered is less than $1 \%$ of the whole 
Table 1: Population potentially exposed to levels above EU limits and WHO guidelines to $\mathrm{NO}_{2}, \mathrm{PM}_{10}$ and $\mathrm{PM}_{2.5}$.

\begin{tabular}{|l|c|c|}
\hline \multirow{2}{*}{ Pollutant } & \multicolumn{2}{|c|}{ Population potentially exposed (\%) } \\
\cline { 2 - 3 } & EU limits & WHO guidelines \\
\hline $\mathrm{NO}_{2}$ & $5 \%$ & $5 \%$ \\
\hline $\mathrm{PM}_{10}$ & $0 \%$ & $1 \%$ \\
\hline $\mathrm{PM}_{2.5}$ & $0 \%$ & $25 \%$ \\
\hline
\end{tabular}

domain, while for $\mathrm{NO}_{2}$ the total area is around $2 \%$. It is important to note that comparing the area covered to the whole domain, it may seem low but the cells with higher values are mainly located in the centre of the Bristol urban area, which combines with the higher population density.

\subsection{Source apportionment}

Based on the concentration fields obtained by the URBAIR model, it is important to comprehend the contributions by each sector considered in the simulations. Overall, the background concentrations have a high impact on the final values. On the obtained simulations, the background contribution values for the peripheral area can achieve over $80 \%$ and for the urban area they can reach up to $60 \%$. For the purpose of this paper it is not relevant to present the background contribution so by this, it was left out of this analysis.

Fig. 3 shows the contribution by sector for $\mathrm{NO}_{2}$ concentrations and since the sector that contributes the most for $\mathrm{NO}_{2}$ concentrations is the transport, it is also presented the average contribution by each transport category. The fleet composition was divided into six major categories: car, bus, van, motor (includes mopeds and motorcycles) and medium and heavy truck.

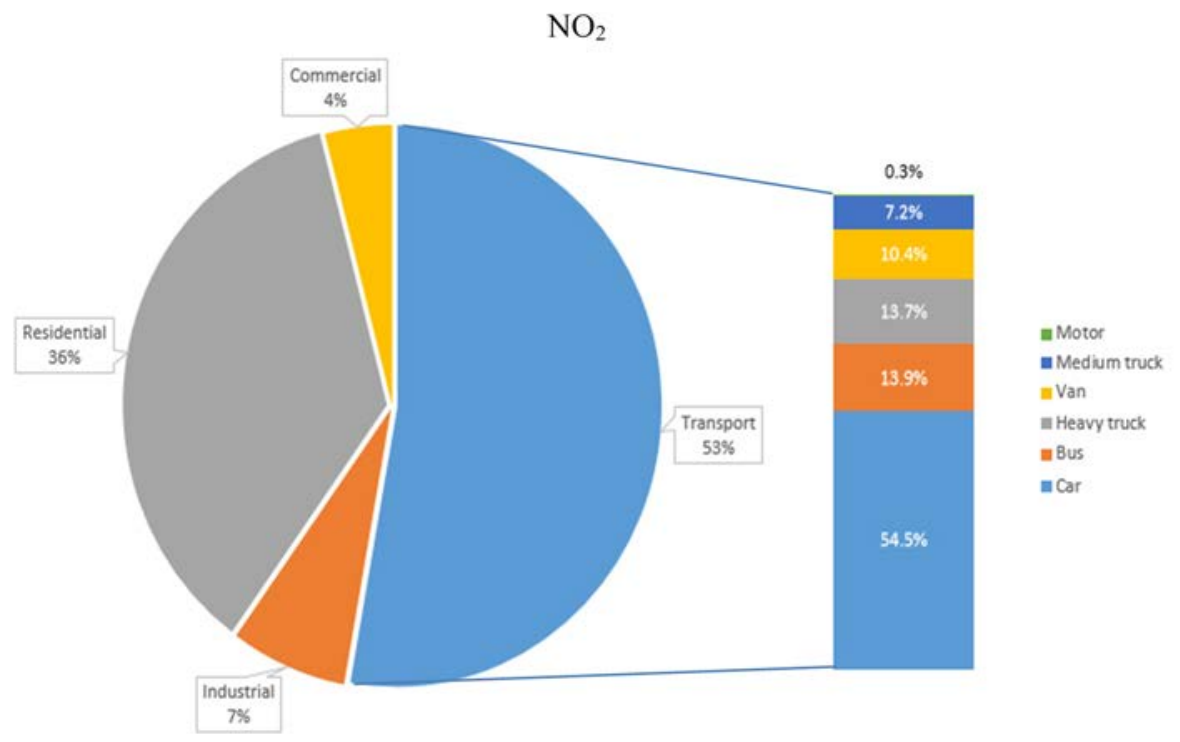

Figure 3: Contribution by sector for $\mathrm{NO}_{2}$ concentrations and contribution by category for transport sector. 
As revealed by Fig. 3, the major contributor is the transport sector. Therefore, to understand behavioural aspects the total concentration for this sector was decomposed into different fleet categories, although for the simulations the fleet composition was divided into weekdays and weekends, only the average composition is presented. Analysing the contribution by category for an average day, as expected the biggest contribution comes from the cars category $(54.5 \%)$, followed by bus $(13.9 \%)$ and heavy truck $(13.7 \%)$.

The total transport concentration for the whole domain indicates a decrease of $25.4 \%$ between a typical weekday and a typical weekend day. In terms of category contribution is noticeable a difference between weekends and weekdays for each category. On weekdays, medium and heavy trucks represent twice the contribution of a typical weekend, where occurs a decrease of the contribution by car, bus and van, while for motor the differences are residual.

Fig. 4 shows the contribution by sector for $\mathrm{PM}_{10}$ concentrations. Residential accounts for $82 \%$ of the total concentration being the major simulated source of particulate matter. The contribution for $\mathrm{PM}_{2.5}$ is assumed to be the same as $\mathrm{PM}_{10}$, therefore only $\mathrm{PM}_{10}$ analysis is presented. The figure below also presents the disaggregation of the total residential concentrations by category. Residential sector was divided into 8 main categories: energy efficient fireplaces/stoves using solid biomass, combustion plants using solid biomass, advanced stoves using solid biomass, combustion plants using hard coal, conventional stoves using solid biomass, fireplaces using solid biomass; and a category denominated "other" which aggregates combustion plants using LPG (liquefied petroleum gas), combustion plants using gas/diesel oil, combustion plants using natural gas and advanced fireplaces using solid biomass.

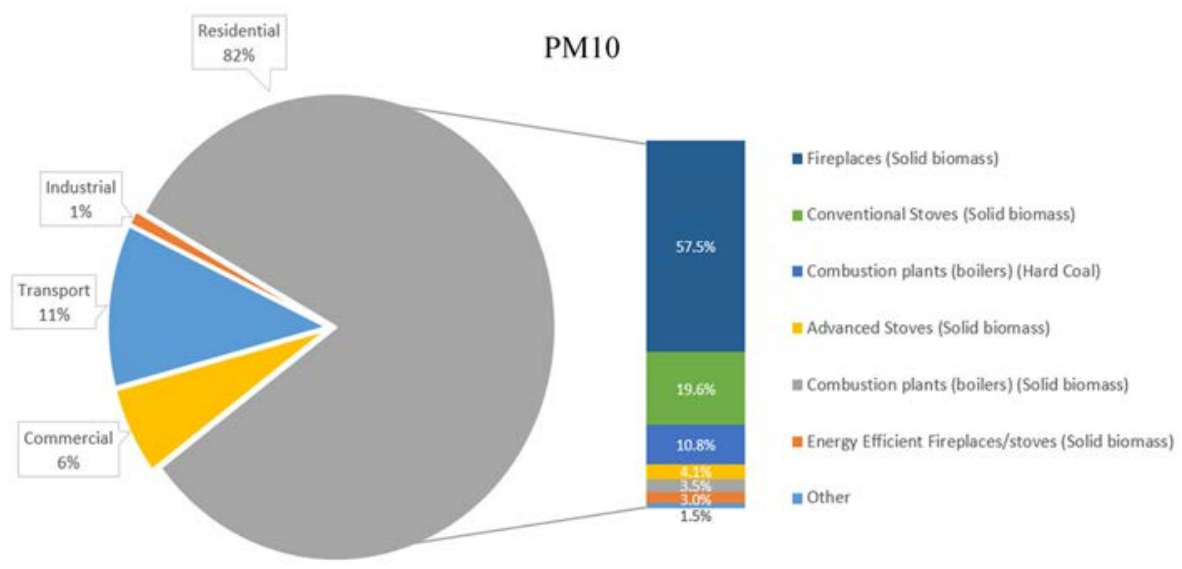

Figure 4: Contribution by sector for $\mathrm{PM}_{10}$ concentrations and contribution by category for the residential sector.

For the residential sector, the category with the highest contribution for particulate matter concentration is fireplaces burning solid biomass $(57.8 \%)$, followed by conventional stoves burning solid biomass (19.6\%) and combustion plants burning hard coal $(10.8 \%)$.

To analyze the behavioral tendencies for the residential sector it was important to examine the daily concentration variation during the year. Fig. 5 represents the concentration on a daily average for particulate matter for the year of 2015 . 


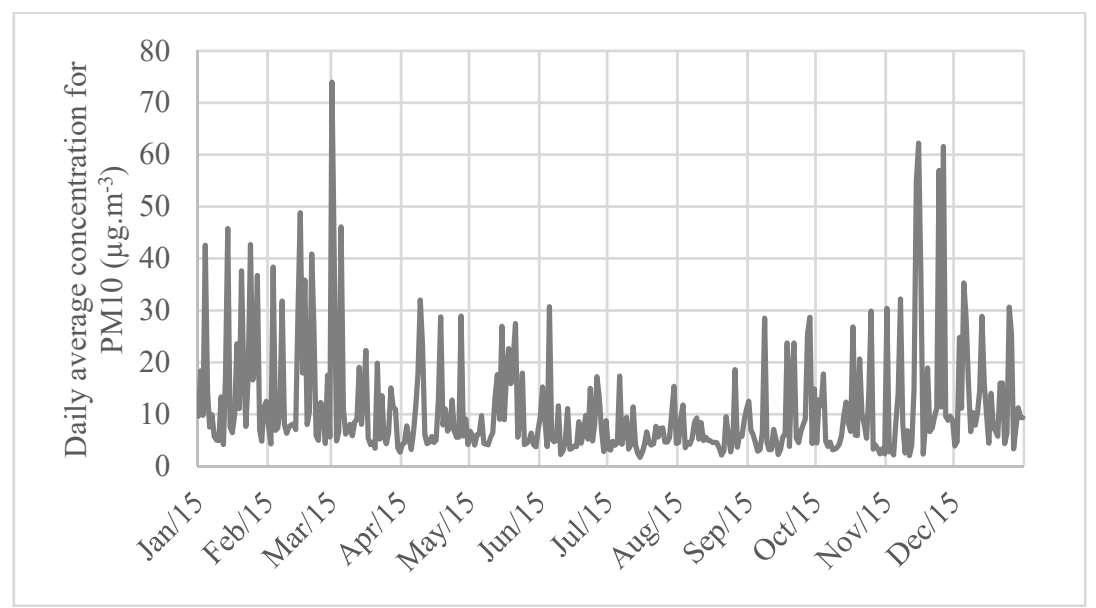

Figure 5: Daily average of $\mathrm{PM}_{10}$ concentrations for 2015. The average of $\mathrm{PM}$ concentrations result from a spatial average over all the domain.

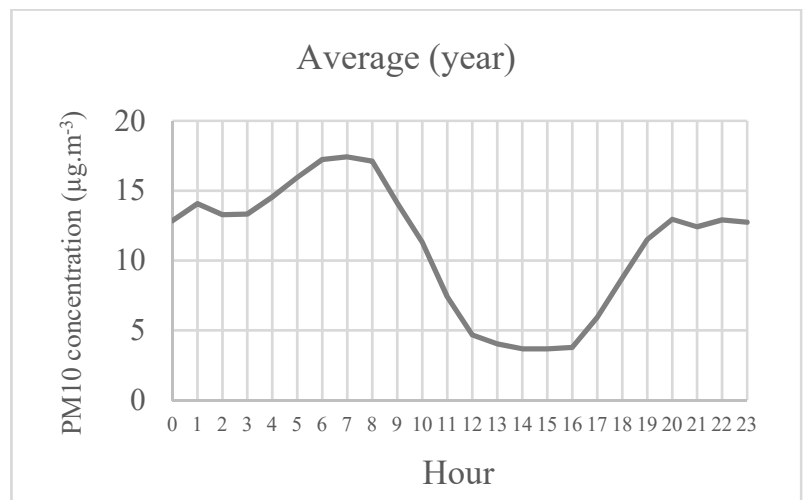

(a)

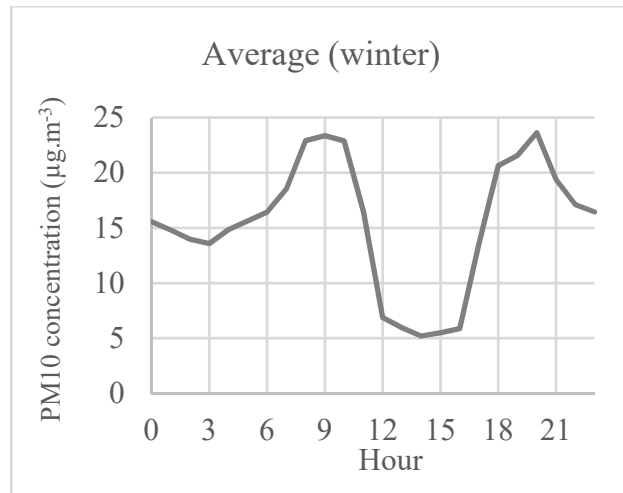

(b)
Average (summer)

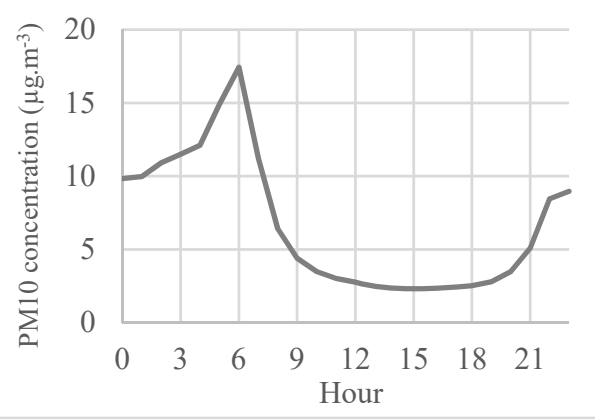

(c)

Figure 6: Average particulate matter concentration for the residential sector by hour for (a) All year; (b) Winter; and (c) Summer. 
The daily average distribution of $\mathrm{PM}_{10}$ concentrations over the year denotes significant differences between winter and summer months. During the colder periods maximum concentrations are achieved and the values are commonly superior to warmer months. This outcome can be easily explained due to the high demand for solid biomass burning for heating purpose during colder periods. This proves to be a good indicator of the behavior of citizens related to energy consumption but also recurring air pollution episodes during winter.

Fig. 6(a) shows the concentration average for the whole year for each hour. Fig. 6(b) and (c) show the concentration average for winter months and for summer months, respectively.

The hourly annual average on Fig. 6 easily distinguishes the peak hours when maximum values are achieved, but also the lowest values periods. The maximums are reached mainly during early mornings between $6 \mathrm{~h}$ and $8 \mathrm{~h}$, and the minimums are roughly at the afternoon around $13 \mathrm{~h}$ and $16 \mathrm{~h}$. When comparing plot (b) and (c), the tendencies are diverse but having a common peak early in the morning. For winter months the values are overall much higher than summer months, showing two maximum periods during the day, being those in the morning between $7 \mathrm{~h}$ and $10 \mathrm{~h}$ and at the end of the day around $18 \mathrm{~h}$ and $21 \mathrm{~h}$. For summer months, the trend is significantly different comparing to the winter. A maximum is reached early in the morning and it is the only peak during the day, having a larger minimum period during the day. These trends can be explained by being majorly incited for heating purposes and related to the population behavior, for example, working and school time schedule.

\section{CONCLUSIONS}

This work focused on the behaviour of the Bristol citizens and its impacts on air quality. The assessment of impacts on air quality was based on $\mathrm{NO}_{2}, \mathrm{PM}_{10}$ and $\mathrm{PM}_{2.5}$ concentrations, taking into account the emissions from residential, commercial, industrial and transport sectors.

Looking at air quality results it is visible for $\mathrm{NO}_{2}$ concentrations the existence of hotspots centred mainly on the urban area. Furthermore, high values are equally observed near the major highways. In terms of exceedances of the EU concentration limits, the only pollutant in disagreement with the law is $\mathrm{NO}_{2}$, but when stricter limits are applied, as established by the World Health Organization, the particulate matter becomes a significant problem for the population exposed where $25 \%$ of the Bristol population is potentially exposed to harmful concentrations of $\mathrm{PM}_{2.5}$.

Focusing on the contribution by sector, the major contributor for $\mathrm{NO}_{2}$ is the transport sector and for particulate matter is the residential sector. Analysing the category contribution for $\mathrm{NO}_{2}$ for the transport sector it was possible to conclude that the major contribution comes from cars $(54.5 \%)$, followed by bus $(13.9 \%)$ and heavy truck $(13.7 \%)$. The distinction between weekday and weekend showed a decrease of concentration of $25.4 \%$ from a typical weekday to weekend. The contribution by category also changed where the biggest difference comes from medium and heavy trucks, where the weekday contribution is twice the values of the weekend.

When considering the contribution of the residential sector and disaggregating into categories, for $\mathrm{PM}_{10}$, the major contribution comes from fireplaces burning solid biomass (57.8\%) followed by conventional stoves burning solid biomass (19.6\%) and combustion plants burning hard coal $(10.8 \%)$. The analysis of the concentration profile by day showed bigger values for colder months comparing to warmer periods, proving that heating is the main purpose. As a result, during winter the concentration values are significantly bigger than during the summer. When observing the hourly variation, the results demonstrate that, as concluded before, the differences are caused by outside temperature but the work/school schedule define the profile tendencies. Therefore, during winter the peak values are during 
morning and at the afternoon/night, achieving low values between $13 \mathrm{~h}$ and $16 \mathrm{~h}$. For summer periods, the results show only one brief peak during morning and followed by a large period of low values.

Future developments under ClairCity project include the continuation of this work by evaluating the impact of citizen's behaviour on air pollution; i.e., considering the disaggregation by citizen's behaviour patterns for example, transport to school, to work, to shopping, etc. Therefore, the main objective is to influence people's knowledge, to encourage change in citizen's behaviour by promoting a more participative society on solving air quality problems and reducing carbon footprint.

\section{ACKNOWLEDGEMENTS}

This work was supported by the ClairCity project. ClairCity has received funding from the European Union's Horizon 2020 research and innovation programme under grant agreement 689289. J. Ferreira is funded by national funds (OE), through FCT - Foundation for Science and Technology, I.P., in the scope of the framework contract foreseen in the numbers 4, 5 and 6 of the article 23, of the Decree-Law 57/2016, of 29 August, changed by Law 57/2017, of 19 July. Thanks are also due for the financial support to the $\mathrm{PhD}$ grant of S. Coelho (SFRH/BD/137999/2018), and to CESAM (UID/AMB/50017/2019), to FCT/MCTES through national funds, and the co-funding by the FEDER, within the PT2020 Partnership Agreement and Compete 2020.

\section{REFERENCES}

[1] European Environmental Agency (EEA), Air quality in Europe: 2018 Report, EEA Report No 12/2018, 2018.

[2] Maas, R. \& Grennfelt, P. (eds), Towards cleaner air. Scientific Assessment Report 2016. EMEP Steering Body and Working Group on Effects of the Convention on Long-Range Transboundary Air Pollution, Oslo, 2016.

[3] European Environmental Agency (EEA), Air quality in Europe: 2014 Report, EEA Report No 5/2014, 2014.

[4] World Health Organization (WHO), Ambient Air Pollution: A Global Assessment of Exposure and Burden of Disease, WHO, 2016.

[5] European Environmental Agency (EEA), Europe's urban air quality: Re-assessing implementation challenges in cities, EEA Report No 24/2018, 2018.

[6] Dias, D. et al., Assessing the importance of transportation activity data for urban emission inventories. Transportation Research Part D-Transport And Environment, 62, pp. 27-35, 2018.

[7] Borrego, C. et al., Urban scale air quality modelling using detailed traffic emissions estimates. Atmospheric Environment, 131, pp. 341-351, 2016. 